\title{
From the chief editor
}

We have immense pleasure in bringing out this inaugural issue of Himalayan Journal of Science and Technology (HiJOST). The journal is the of cial publication of Central Campus of Technology, Dharan, Tribhuvan University, Nepal. The concept of a scienti c journal was discussed few years ago among the faculty members of this institute and its urgent need was felt. Consequently, a goal of publishing journal with highest scienti $\mathrm{c}$ and statistical quality was made and this journal is the outcome of what has been done in this eld within a short period of time.

Central Campus of Technology has many departments under which different courses are run at Bachelor and Master levels such as Food Technology, Microbiology, Nutrition, Geology, Statistics, Mathematics, Physics, Chemistry, Zoology and Botany. The graduate and post graduate students studying in these faculties have to carry out research and project works during their study period. Moreover, faculties are also actively involved in various in-house and funded research projects. Therefore, this journal will act as a means of disseminating their ndings to the scienti c community. HiJOST accepts manuscripts in the form of original research articles, review articles, letter to the editor, short communications and research notes in Himalayan Journal of Science and Technology (HiJOST) is the peer reviewed journal published annually. This journal has been launched with the objective of publishing research papers in the elds of Basic and Applied Sciences, Technology, Engineering and Medical Sciences. On the behalf of the whole editorial team, I sincerely thank all our contributors and well wishers for supporting us in this grand venture. Any suggestions and comments regarding the journal are highly welcomed. Hoping for wider audience and receiving a large number of manuscripts for the upcoming issue.

Thank you

(Prof. Dr. Dhan Bahadur Karki)

Chief Editor 